\title{
Zastosowanie audiometrii wysokich częstotliwości w diagnostyce nagłego niedosłuchu u muzyka
}

\section{High frequency audiometry usage in sudden hearing loss in musicians}

\author{
Paulina Krasnodębska1, Danuta Raj-Koziak ${ }^{1}$, Agata Szkiełkowska ${ }^{1,2}$, Henryk Skarżyński ${ }^{1,2}$ \\ ${ }^{1}$ Instytut Fizjologii i Patologii Słuchu, Światowe Centrum Słuchu, Klinika Audiologii i Foniatrii, \\ Warszawa/Kajetany \\ ${ }^{2}$ Uniwersytet Muzyczny Fryderyka Chopina, Katedra Audiologii i Foniatrii, Warszawa
}

Adres autora: Paulina Krasnodębska, Światowe Centrum Słuchu, Klinika Audiologii i Foniatrii, ul. Mokra 17, Kajetany, 05-830 Nadarzyn, e-mail: p.krasnodebska@ifps.org.pl

\section{Streszczenie}

Narząd słuchu odgrywa szczególną rolę u osób wykorzystujących słuch w pracy zawodowej (muzyków, reżyserów dźwięku). Nagłe pogorszenie słuchu często występujące niezależnie lub równolegle z szumami usznymi może im znacznie utrudniać wykonywanie pracy. Pogorszenie progu słyszenia o co najmniej $30 \mathrm{~dB}$ dla trzech sąsiadujących częstotliwości oktawowych tonów słyszalnych stanowi obecnie kryterium rozpoznania nagłej głuchoty. U osób zawodowo posługujących się słuchem już dużo mniejszy ubytek słuchu, często dla częstotliwości spoza zakresu oznaczanego w standardowej audiometrii tonalnej, może powodować znaczny dyskomfort w pracy zawodowej. Dlatego konieczne jest zwrócenie szczególnej uwagi na tę grupę zawodową pod kątem ustalenia rekomendowanych procedur postępowania w sytuacji nagłego pogorszenia słuchu, nawet jeśli niedosłuch nie spełnia kryteriów nagłej głuchoty. Zasadne wydaje się również opracowanie odrębnych standardów dla tej grupy zawodowej.

Słowa kluczowe: nagła głuchota • audiometria wysokich częstotliwości • muzyk • szumy uszne

\begin{abstract}
The auditory system occupies a crucial role for the professionals who use hearing at work (musicians, sound directors). The sudden hearing loss that frequently occurs with tinnitus (either as an independent or a concominant phenomenon), can significantly deteriorate the subjects' job performance. At present, the decrease in the hearing threshold of at least $30 \mathrm{~dB}$ at the three subsequent octave frequencies is a criterion for the diagnosis of the sudden deafness. In people who use hearing professionally even much subtle hearing loss (often at the frequencies not examined in the standard pure tone audiometry) results in significant discomfort. Therefore, it is necessary to pay special attention to this group of professionals in order to determine the recommended procedures in the sudden hearing loss, even if the hearing does not meet the criteria for the sudden deafness. It is conceivable that the separate diagnostic and treating standards in this group should be developed.
\end{abstract}

Key words: sudden hearing loss $\bullet$ extended high frequency audiometry $\bullet$ musician $\bullet$ tinnitus

\section{Wprowadzenie}

Ludzkie ucho zdolne jest odbierać dźwięki o częstotliwościach od $16 \mathrm{~Hz}$ do $20 \mathrm{kHz}$. Spotykane najczęściej w codziennym życiu dźwięki, których szczególnym przykładem jest mowa ludzka, mieszczą się w zakresie od $125 \mathrm{~Hz}$ do $8 \mathrm{kHz}$ [1]. Zakres odbioru mowy ludzkiej oceniany jest w badaniu audiologicznym poprzez oznaczenie poziomu progu słyszenia. Standardowe audiometry kliniczne mierzą przewodnictwo powietrzne w zakresie od $125 \mathrm{~Hz}$ do $8 \mathrm{kHz}$ i przewodnictwo kostne w zakresie od $250 \mathrm{~Hz}$ do $4 \mathrm{kHz}$ [2]. Kryterium kliniczne poziomu prawidłowego słuchu w audiometrii tonalnej, zgodnie z wytycznymi Światowej Organizacji Zdrowia, odnosi się do wartości nieprzekraczających 20 dB HL [3,4].

Narząd słuchu odgrywa szczególną rolę u osób wykorzystujących słuch w pracy zawodowej (muzyków, reżyserów dźwięku). Percepcja słuchowa w tej grupie osób jest dużo szersza w porównaniu z ogółem populacji [5]. Nagłe pogorszenie słuchu często występujące niezależnie lub równolegle z szumami usznymi może im znacznie utrudniać wykonywanie pracy. Zgodnie z najnowszymi wytycznymi Polskiego Towarzystwa Audiologicznego i Foniatrycznego 

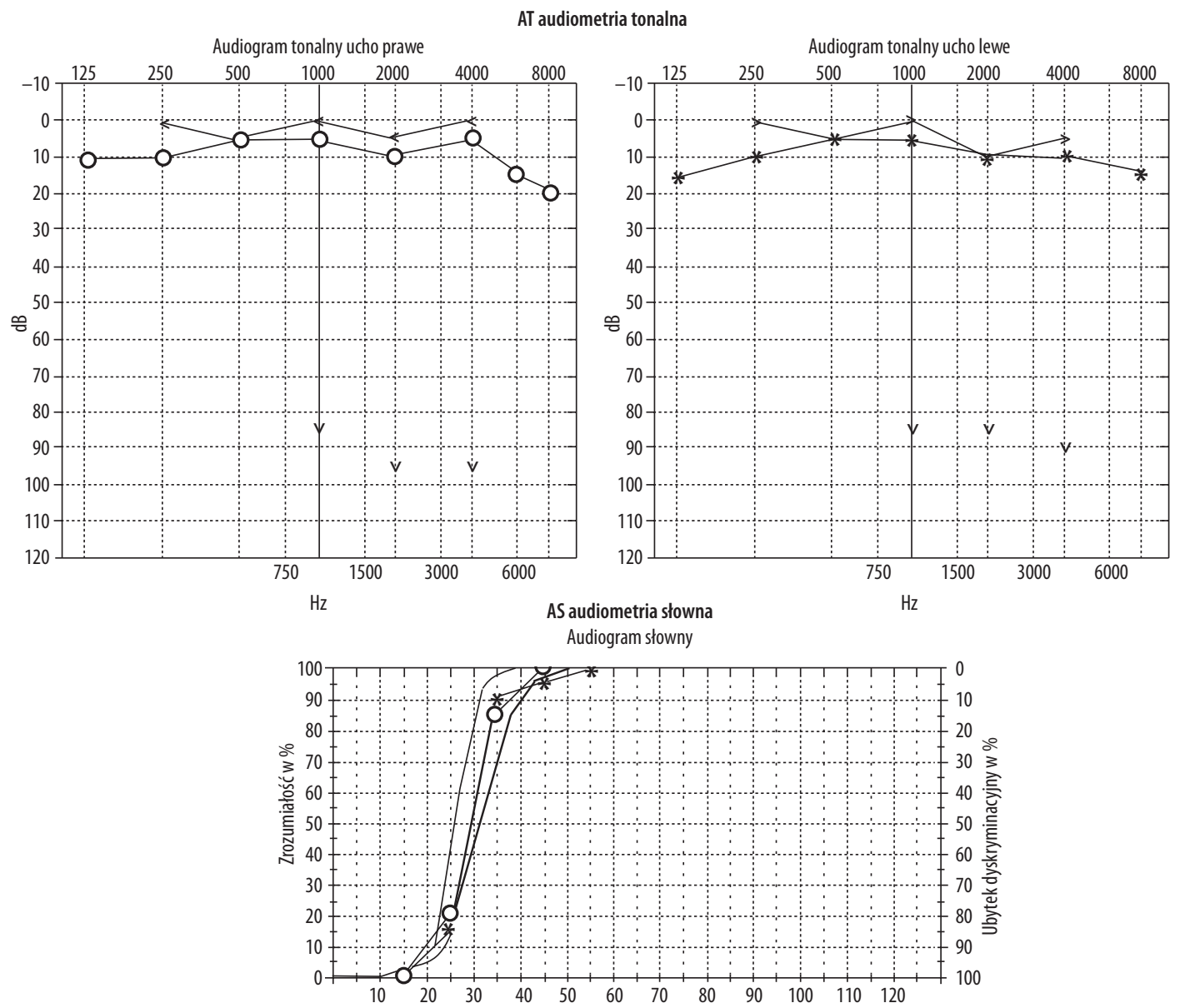

Poziom sygnału mowy [dB SPL] czewrony - test liczbowy, pomarańczowy - test wyrazowy

Rycina 1. Wynik audiometrii tonalnej oraz audiometrii słownej

Figure 1 . The result of the pure tone audiometry and the speech audiometry

z 2015 roku, nagły niedosłuch definiuje się jako gwałtownie rozwijające się w ciągu 72 godzin pogorszenie słuchu w jednym uchu lub rzadziej w obojgu uszach, o głębokości $\geq 30 \mathrm{~dB}$ w zakresie 3 sąsiadujących częstotliwości oktawowych [6]. U osób zawodowo posługujących się słuchem już dużo mniejszy ubytek słuchu, często dla częstotliwości spoza zakresu oznaczanego w standardowej audiometrii tonalnej, powoduje znaczny dyskomfort i jest przyczyną trudności w wykonywaniu pracy zawodowej [7]. Dlatego konieczne jest zwrócenie szczególnej uwagi na tę grupę zawodową pod kątem ustalenia rekomendowanych procedur postępowania w sytuacji nagłego pogorszenia słuchu, nawet jeśli niedosłuch nie spełnia kryteriów nagłej głuchoty.

Celem pracy był opis przypadku nagłego wysokoczęstotliwościowego niedosłuchu u muzyka. Autorzy poddali analizie panel diagnostyczny stosowany w nagłej głuchocie oraz wskazania do włączenia terapii w przypadku pacjenta zawodowo posługującego się słuchem.

\section{Prezentacja przypadku}

28-letnia kobieta, z wykształcenia muzyk (dyrygent i wiolonczelistka), zauważyła u siebie szumy w uchu prawym, poprzedzone uczuciem zatkanego ucha. Szumom usznym towarzyszył niedosłuch oraz problemy ze zrozumieniem mowy w hałasie. Pacjentka była wcześniej leczona z powodu choroby immunologicznej tarczycy, oporności insulinowej $\mathrm{z}$ hiperinsulinizmem oraz nadwagi.

Z powodu szumów usznych i niedosłuchu poszukiwała pomocy w poradni otolaryngologicznej oraz szpitalnej izbie przyjęć kilku placówek, gdyż w badaniu przedmiotowym nie stwierdzano odchyleń od stanu prawidłowego. W zleconych badaniach dodatkowych oceniających próg słyszenia $\mathrm{w}$ audiometrii tonalnej stwierdzano prawidłowy poziom słyszenia w całym badanym zakresie częstotliwości od $0,125 \mathrm{~Hz}$ do $8 \mathrm{kHz}$.

Do Instytutu Fizjologii i Patologii Słuchu pacjentka trafiła po kilku tygodniach od wystąpienia objawów. We wstępnym badaniu otolaryngologicznym nie stwierdzano odchyleń od stanu prawidłowego. W badaniach oceniających próg słyszenia $\mathrm{w}$ audiometrii tonalnej oraz audiometrii słownej obustronnie wyniki mieściły się w granicach normy (rycina 1). W badaniu audiometrii impedancyjnej zarejestrowano obustronnie tympanogram A oraz odruchy z mięśnia strzemiączkowego przy stymulacji ipsilateralnej 


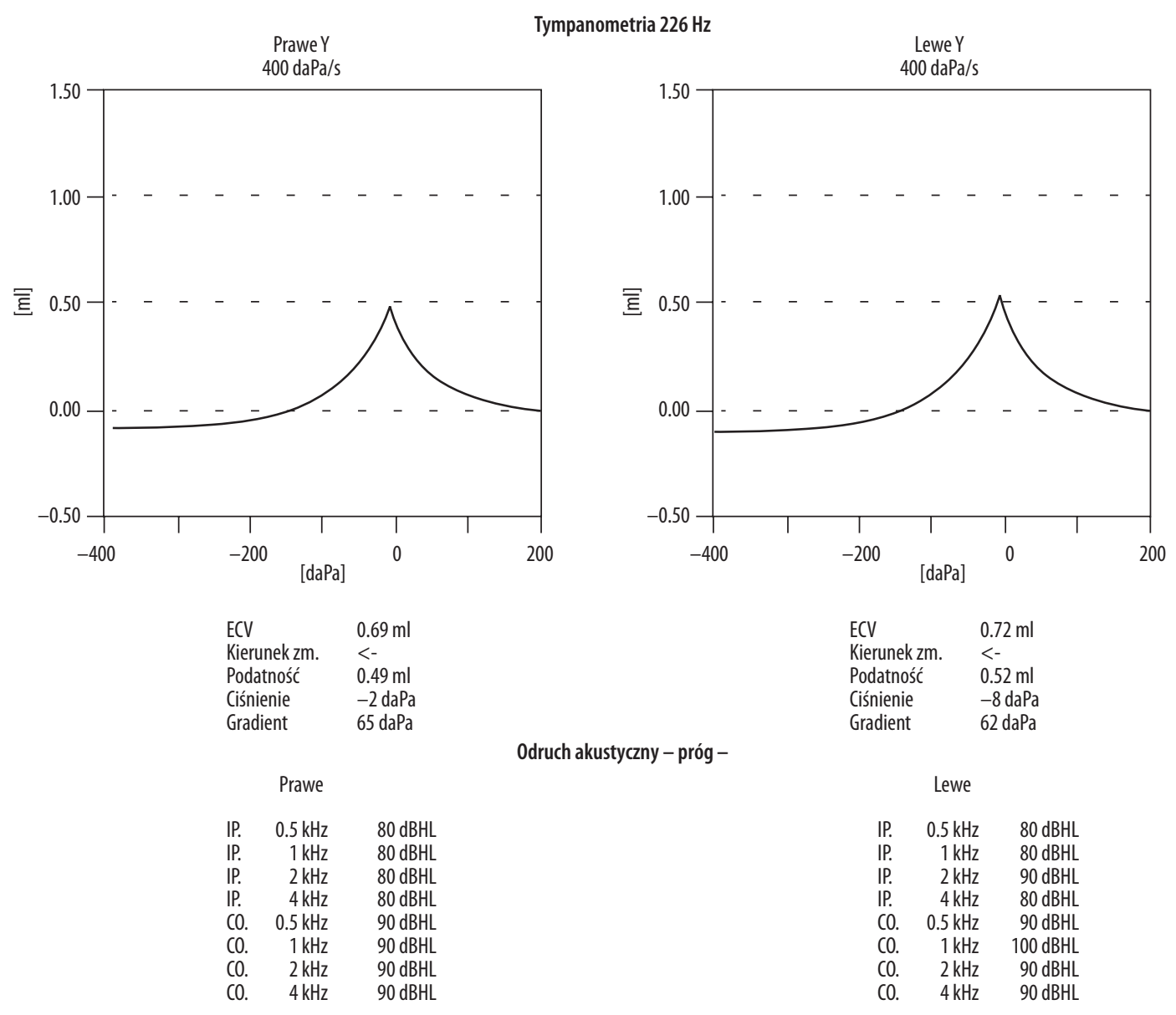

Rycina 2. Wynik audiometrii impedancyjnej

Figure 2. The result of the impedance audiometry

i kontralateralnej (rycina 2). Ocena progu nieprzyjemnego słyszenia (ang. Uncomfortable Loudness Level, UCL) wykazała nieprzyjemny odbiór dźwięków na poziomie $85 \mathrm{~dB}$ dla częstotliwości $1 \mathrm{kHz}$; $95 \mathrm{~dB}$ dla $2 \mathrm{kHz}$ i $4 \mathrm{kHz}$ w uchu prawym oraz $85 \mathrm{~dB}$ dla $1 \mathrm{kHz}$ i $2 \mathrm{kHz}$ oraz $90 \mathrm{~dB}$ dla $4 \mathrm{kHz}$ w uchu lewym. W badaniach psychoakustycznych oceniających szumy uszne pacjentka określała je jako dźwięki zbliżone do tonu o częstotliwości $4 \mathrm{kHz}$ i natężeniu $15 \mathrm{~dB}$. Minimalny poziom maskowania (ang. Minimal Masking Level, MML) w uchu prawym wyniósł $30 \mathrm{~dB}$, w uchu lewym $40 \mathrm{~dB}$. W badaniu produktów zniekształceń nieliniowych otoemisji akustycznych (ang. Distortion Product Otoacoustic Emissions, DPOAE) stwierdzono obniżenie amplitudy sygnału w uchu prawym dla częstotliwości $10 \mathrm{kHz}$, a w uchu lewym prawidłową amplitudę sygnału dla całego pasma badanych częstotliwości w zakresie od $1 \mathrm{kHz}$ do $10 \mathrm{kHz}$. Ocena potencjałów wywołanych z pnia mózgu w badaniu ABR latencje wykazała prawidłową morfologię oraz parametry czasowe zapisu.

Pacjentka w wywiadzie subiektywnie lokalizowała ubytek słuchu w zakresie około $12 \mathrm{kHz}$ w uchu prawym, co wynikało prawdopodobnie z jej predyspozycji własnych i wykształcenia muzycznego. W wykonanym badaniu audiometrii wysokich częstotliwości, które nie jest rutynowo wykonywanym badaniem w praktyce audiologicznej, potwierdzono niedosłuch wysokoczęstotliwościowy (rycina 3). W badaniu uwidoczniono asymetrię w zakresie od $9 \mathrm{kHz}$ do $16 \mathrm{kHz}$ pomiędzy prawym a lewym uchem na niekorzyść ucha prawego. Stwierdzono podwyższenie progu słyszenia od $9 \mathrm{kHz}$ do $16 \mathrm{kHz}$ w uchu prawym o ponad $40 \mathrm{~dB}$ HL w stosunku do ucha lewego. Zdiagnozowany wysokoczęstotliwościowy niedosłuch w uchu prawym nie spełniał kryteriów nagłej głuchoty.

U pacjentki zastosowano leczenie nagłej głuchoty zgodne ze standardami rekomendowanymi przez Polskie Towarzystwo Audiologiczne i Foniatryczne. Zastosowano:

- kortykosteroidoterapię dożylną - deksametazon 1×10 mg przez $7 \mathrm{dni}$, następnie zmniejszano dawkę leku o $2 \mathrm{mg}$ co 2 dni,

- leki poprawiające krążenie mózgowe oraz poprawiające ukrwienie ucha wewnętrznego - nicergolina $2 \times 20 \mathrm{mg}$ doustnie przez $10 \mathrm{dni}$,

- omeprazol 2×20 mg doustnie, jako osłonę błony śluzowej żołądka podczas stosowanej kortykoterapii,

- wykonano próbę leczenia w komorze hiperbarycznej, jednak ze względu na współistniejącą infekcję górnych dróg oddechowych i zgłaszany ból uszu przy próbie wykonania terapii, odstąpiono od zabiegów. 

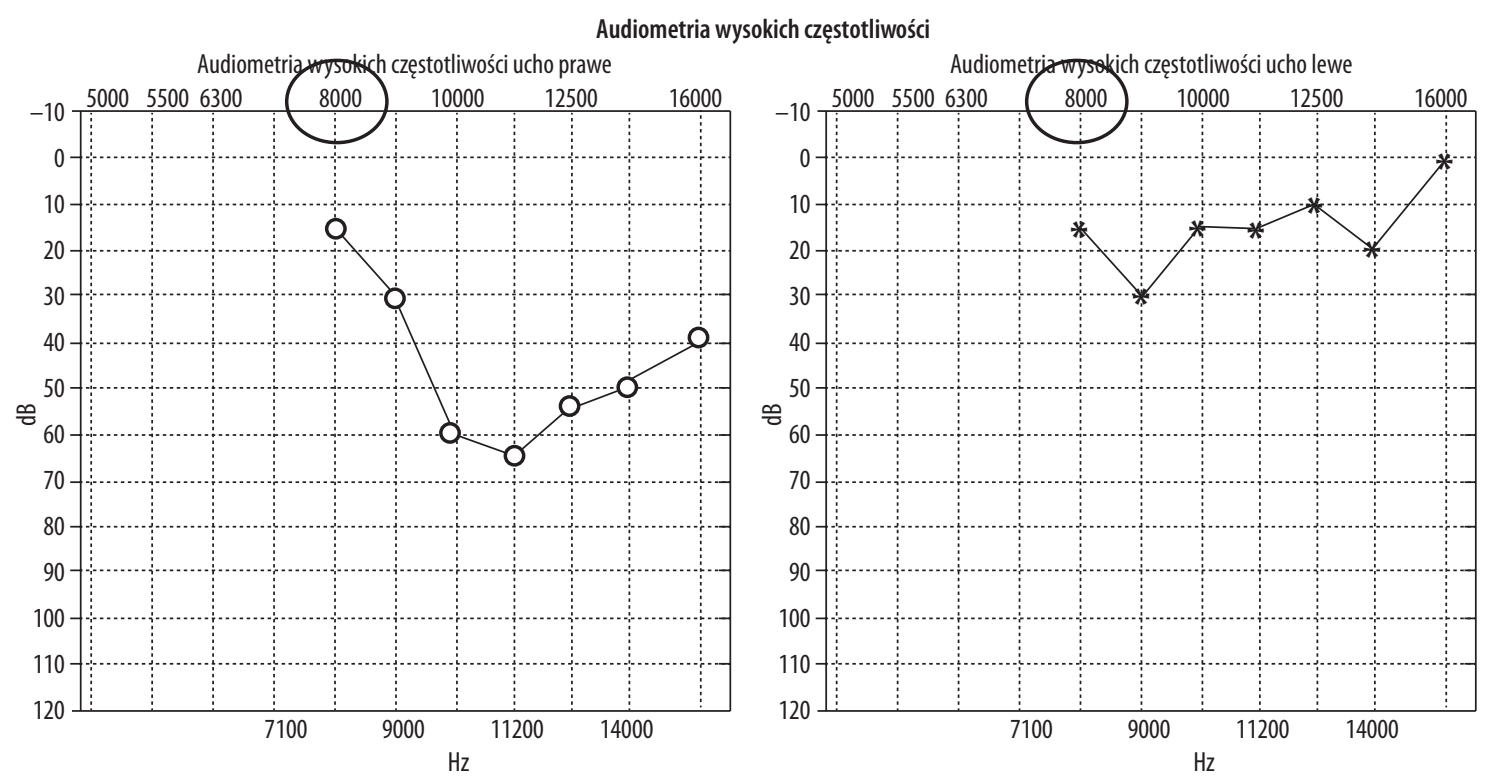

Rycina 3. Wynik audiometrii wysokich częstotliwości

Figure 3. The result of the high-frequency audiometry

Po zastosowanym leczeniu nie uzyskano obiektywnej poprawy słuchu. Pacjentka subiektywne zgłaszała zmniejszenie nasilenia szumów usznych.

\section{Dyskusja}

Grupa osób zawodowo posługujących się słuchem wyróżnia się częstszym występowaniem pohałasowych uszkodzeń słuchu w stosunku do całej populacji [8]. W $2014 \mathrm{r}$. zostały opublikowane wyniki dotyczące zgłaszania nowych zachorowań z powodu niedosłuchu izolowanego lub niedosłuchu z towarzyszącymi szumami usznymi w Niemczech. Badanie dotyczyło grupy ponad 3 miliona ludzi, wśród których ponad 2200 było profesjonalnymi muzykami. Zauważono, iż u muzyków w stosunku do pozostałych osób 3,51-krotnie częściej występowało pogorszenie słuchu wywołane hałasem i 1,45-krotnie częściej szumy uszne [8]. Autorzy badania zauważyli ponadto, iż systemy zdrowotne nie są dobrze przygotowane do diagnostyki pacjentów wykonujących zawód muzyka lub czynności zawodowe związane bezpośrednio z muzyką. Wyniki badań przeprowadzonych wśród studentów konserwatoriów muzycznych wykazały, że w przypadku wystąpienia u siebie problemu zdrowotnego studenci szukali w pierwszej kolejności pomocy u nauczycieli, zanim udali się do lekarza [9]. Ze względu na zwiększone ryzyko uszkodzenia słuchu w grupie muzyków i reżyserów dźwięku konieczne jest kształtowanie świadomości zdrowotnej odnoszącej się do problemów audiologicznych u osób profesjonalnie posługujących się słuchem. Diagnostyka i leczenie uszkodzeń, które mogą prowadzić do trwałego uszkodzenia narządu słuchu, powinny być przeprowadzane jak najwcześniej i jak najtrafniej w tej grupie zawodowej.

$\mathrm{W}$ przeszłości istniały problemy z wykonywaniem wiarygodnych i powtarzalnych badań poziomu progu słyszenia dla wysokich częstotliwości. Postęp techniki umożliwił seryjną produkcję, a tym samym łatwiejszy dostęp, audiometrów klinicznych i przetworników do badań przewodnictwa kostnego i powietrznego na częstotliwościach ponad $8 \mathrm{kHz}$ [1]. Współcześnie badanie audiometrii wysokich częstotliwości wykorzystywane jest przede wszystkim w profilaktyce pohałasowych uszkodzeń słuchu, jak również w diagnostyce osób narażonych na przemysłowe działanie hałasu [10-12]. Panel diagnostyki audiologicznej standardowo zawiera audiometrię wysokich częstotliwości również w przypadku polekowych uszkodzeń słuchu [13].

Ze względu na szerszą, w stosunku do ogółu populacji, percepcję słuchową osób z wykształceniem muzycznym wydaje się zasadne włączenie audiometrii wysokich częstotliwości do rutynowo wykonywanego u tych osób zestawu badań diagnostycznych. Standardowo stosowana w tej grupie zawodowej diagnostyka audiologiczna progu słyszenia dla przewodnictwa powietrznego w zakresie od $125 \mathrm{~Hz}$ do $16 \mathrm{kHz}$ umożliwi łatwiejszą diagnostykę w przypadku nagłego niedosłuchu wysokoczęstotliwościowego. Ponadto włączenie w tej grupie osób audiometrii wysokich częstotliwości do badań okresowych słuchu ułatwiłoby podjęcie decyzji o rozpoznaniu i włączeniu ewentualnego leczenia w przypadku nagłej głuchoty. Decyzja o podjęciu leczenia powinna być podejmowana zawsze indywidualnie, szczególnie u osób posługujących się zawodowo słuchem.

Niniejszym artykułem chcielibyśmy zapoczątkować dyskusję na temat szczególnego potraktowania problemu nagłego niedosłuchu i nagłych szumów usznych u osób zawodowo posługujących się słuchem. Konieczna jest analiza szerszego materiału w celu wypracowania jednolitych procedur postępowania.

\section{Wnioski}

1. Należy rozważyć włączenie audiometrii wysokich częstotliwości w standardowy panel diagnostyczny u pacjentów z nagłym niedosłuchem. 
2. U osoby wykorzystującej słuch w pracy zawodowej decyzja o włączeniu terapii z powodu pogorszenia się słuchu powinna być podejmowana indywidualnie.

\section{Piśmiennictwo:}

1. Gierek T. Audiometria wysokoczęstotliwościowa. Audiologia kliniczna. Śliwińska-Kowalska M, red. Łódź; 2005: 121-23.

2. Fabijańska A, Smurzyński J, Kochanek K, Skarżyński H. Audiometria wysokich częstotliwości u pacjentów z szumami usznymi i prawidłowym słuchem. Now Audiofonol, 2014;3(3): PB17-23.

3. Śliwińska-Kowalska M. Kryteria oceny słyszenia u osób wykonujących pracę wymagającą dobrej sprawności słuchu. Otorynolaryngologia, 2013; 12(3): 105-13.

4. Stephens D. Audiological terms. Definitions, protocols and guidelines in genetic hearing impairment. London: Whurr, 2001; 9-14.

5. Seither-Preisler A, Johnson L, Krumbholz K, Nobbe A, Patterson R, Seither S i wsp. Tone sequences with conflicting fundamental pitch and timbre changes are heard differently by musicians and nonmusicians. J Exp Psychol Hum Percept Perform, 2007; 33(3): 743-51.

6. Śliwińska-Kowalska M, Narożny W, Sekula A, Pawlak-Osińska K, Morawski K, Kot J i wsp. Nagły niedosłuch czuciowo-nerwowy - stanowisko Polskiego Towarzystwa Audiologicznego i Foniatrycznego dotyczące zaleceń diagnostycznych i terapeutycznych. Otolaryngologia, 2015; 14(2): 65-73.
7. Jansen E, Helleman H, Dreschler W, de Laat J. Noise induced hearing loss and other hearing complaints among musicians of symphony orchestras. Int Arch Occupa Environ Health, 2009; 82(2): 153-64.

8. Schink T, Kreutz G, Busch V, Pigeot I, Ahrens W. Incidence and relative risk of hearing disorders in professional musicians. Occup Environ Med, 2014; 71(7): 472-76.

9. Williamon A, Thompson S. Awareness and incidence of health problems among conservatoire students. Psychology of Music, 2006; 34: 411-30.

10. Balatsouras D, Homsioglou E, Danielidis V. Extended highfrequency audiometry in patients with acoustic trauma. Clin Otolaryngol, 2005; 30(3): 249-54.

11. Somma G, Pietroiusti A, Magrini A, Coppeta L, Ancona C, Gardi S i wsp. Extended high-frequency audiometry and noise induced hearing loss in cement workers. Am J Ind Med, 2008; 51(6): 452-62.

12. Korres G, Balatsouras D, Tzagaroulakis A, Kandiloros D, Ferekidis E. Extended high-frequency audiometry in subjects exposed to occupational noise. B-ENT, 2007; 4(3): 147-55.

13. Arora R, Thakur J, Azad R, Mohindroo N, Sharma D, Seam R. Cisplatin-based chemotherapy: Add high-frequency audiometry in the regimen. Indian J Cancer, 2009; 46(4): 311-17. 